\title{
Ventilator-Induced Lung Injury: Classic and Novel Concepts
}

\author{
Bhushan H Katira
}

\author{
Introduction \\ Classic Concept \\ Heart-Lung Interactions Can Contribute to VILI \\ Lung Deflation Injury \\ Effort-Induced Lung Injury \\ Summary
}

\begin{abstract}
Ventilator-induced lung injury (VILI) is a central confounder to improving outcomes from use of positive-pressure ventilation in critical illness. Therefore, with increasing use of positive-pressure ventilation, awareness to prevent VILI has grown. Because VILI cannot be diagnosed at the bedside, its prevention can only be attained by identifying the clinical mechanisms of harm, such as high tidal volume, high plateau pressure, and so forth, which, in turn, are derived from decades of laboratory work. The practice of positive-pressure ventilation has undergone a significant change; most important in the past decade is the preference to use noninvasive ventilation. Although noninvasive ventilation prevents the complications of intubation, it has potential to cause harm, especially in patients with de novo respiratory failure. This review covers some of the classic and emerging concepts of VILI genesis and their role during noninvasive ventilation. Combined modulation of these mechanisms could have a potential to impact outcomes. Key words: ventilatorinduced lung injury; heart-lung interaction; lung deflation; effort-induced lung injury. [Respir Care 2019;64(6):629-637. (C) 2019 Daedalus Enterprises]
\end{abstract}

\section{Introduction}

Positive-pressure ventilation came into vogue with the 1950s polio outbreak ${ }^{1}$ and has become the very foundation of critical care practice. Over the past 7 decades, the method

\footnotetext{
Dr Katira is affiliated with Translational Medicine, The Research Institute, Hospital for Sick Children, Toronto, Ontario, Canada; Department of Critical Care Medicine, Hospital for Sick Children, University of Toronto, Toronto, Ontario, Canada; and Interdepartmental Division of Critical Care Medicine, University of Toronto, Toronto, Ontario, Canada.

Dr Katira presented a version of this paper at the 57th RESPIRATORY CARE Journal Conference, Noninvasive Respiratory Support in Adults, held June 14-15, 2018, in St Petersburg, Florida.
}

Correspondence: Bhushan H Katira MBBS, Translational Medicine, The Research Institute, Hospital for Sick Children, 686 Bay St, Toronto, ON M5G 0A4, Canada. E-mail: bhushan.katira@ sickkids.ca.

DOI: $10.4187 /$ respcare.07055 of delivering positive-pressure ventilation has significantly evolved with more sophistication and user friendliness. ${ }^{2}$ It is a life-saving therapy and, if instituted correctly, can alter outcomes in disease states, such as ARDS and asthma. It can now be delivered without intubation, referred to as noninvasive ventilation (NIV), and has revolutionized the practice, especially in the field of long-term and/or home use.

However, despite being beneficial, positive-pressure ventilation can harm the lungs in several ways and lead to what is called ventilator-induced lung injury (VILI). This was understood in the early days of mechanical ventilation, and the term respirator lung was used to identify lung injury on autopsy of patients exposed to positive-pressure ventilation during the polio epidemic. ${ }^{3}$ Over the past 5 decades, VILI has been extensively studied and several mechanisms of harm have been identified. ${ }^{4}$ It is important to understand VILI because it can confound outcomes, especially in the presence of significant lung disease of any 
cause. This paper briefly described the origin of some of the classic concepts and the impact of their implementation. It also discusses a few emerging concepts around VILI genesis: the contribution of hemodynamics and spontaneous breathing.

\section{Classic Concept}

As far back as the 1960s, by using several canine lung lobes, Faridy et $\mathrm{al}^{5}$ showed that increasing tidal volume $\left(\mathrm{V}_{\mathrm{T}}\right)$ and lowering PEEP resulted in lower lung volume for the same transpulmonary pressure. They concluded that high $\mathrm{V}_{\mathrm{T}}$ and low PEEP resulted in higher surface forces. It is known today that high surface forces (as caused by surfactant depletion) lead to collapse and inflammation (ie, VILI). Thereafter, in 1970, Mead et $\mathrm{al}^{6}$ demonstrated a wide range of shear strain distribution in a model of heterogeneous lung disease, which thus provided a mechanical basis of VILI. Later in 1974, Webb and Tierney ${ }^{7}$ published the first in vivo study of VILI. They showed that healthy rats ventilated with peak airway pressures of $45 \mathrm{~cm} \mathrm{H}_{2} \mathrm{O}$ and no PEEP died from florid (and hemorrhagic) pulmonary edema within 20-30 min; whereas adding a PEEP of $10 \mathrm{~cm} \mathrm{H}_{2} \mathrm{O}$ while keeping the same peak airway pressure caused minimum or no lung injury. ${ }^{7}$ Vascular interdependence (high hydrostatic pressure) was postulated as the cause of pulmonary edema. ${ }^{7}$ This was a key paper in the field and inspired much research.

In the early 1980s, key papers demonstrated that high $\mathrm{V}_{\mathrm{T}}$ ventilation caused pulmonary edema by increasing microvascular permeability, which led to protein and water leak as well as inflammation. ${ }^{8}{ }^{8}$ Limiting $\mathrm{V}_{\mathrm{T}}$ while keeping the airway pressure similar protected the lung, which thus separated barotrauma from volutrauma. ${ }^{10,11}$ These evolving concepts led to the principle of lung-protective strategies and paved the path for clinical studies by Hickling et al ${ }^{12,13}$ who showed, in 2 different observational papers in the early $1990 \mathrm{~s}$, that limiting $\mathrm{V}_{\mathrm{T}}$ to achieve "permissive hypercapnia" improved the predicted mortality in subjects with acute respiratory failure. An interesting concept of biotrauma was postulated by Slutsky and colleagues, who, initially, in preclinical models, followed by clinical study, ${ }^{14-16}$ showed that high $V_{T}$ ventilation led to expression of inflammatory mediators and neutrophil recruitment (biological consequence of biophysical factors). This, they thought, could contribute toward multiple organ dysfunction, a frequent complication in critical illness.

Eventually, a randomized control trial by Amato et al, ${ }^{17}$ in the late 1990s, and ARDSnet, ${ }^{18}$ in 2000, demonstrated significant mortality benefit by reducing $\mathrm{V}_{\mathrm{T}}$ in subjects with ARDS during invasive ventilation. However, over the past decade, NIV was being increasingly used for de novo respiratory failure. Although it avoids intubation, it may have an impact on VILI and, therefore, on outcomes in ARDS. In a recent study, Carteaux et $\mathrm{al}^{19}$ reported that the use of exhaled $\mathrm{V}_{\mathrm{T}}$ during NIV (with an ICU ventilator circuit able to monitor exhaled volume) was an independent risk factor for NIV failure when the predicted body weight was $>9.5 \mathrm{~mL} / \mathrm{kg}$. $\mathrm{V}_{\mathrm{T}}$ is usually not measured during NIV, and clinical response is inferred by reduction of respiratory effort. A high effort would mean high $\mathrm{V}_{\mathrm{T}}$, and persistence of such high effort has been postulated to cause patient's self-inflicted lung injury. ${ }^{20}$ So, whether it is the ventilator that delivers the high $\mathrm{V}_{\mathrm{T}}$ or the patient who breathes it in, the resultant effect is propagation of lung injury (Table 1).

As demonstrated by Webb and Tierney, ${ }^{7}$ PEEP was protective for pulmonary edema and, hence, an integral part of lung-protective ventilation. In most disease states, PEEP can be set according to an oxygenation response. However, in heterogenous lung disease, such as ARDS, determining the optimal PEEP is challenging because low PEEP can cause atelectasis and high PEEP can cause overinflation. Despite several physiologic studies that demonstrate the benefits of optimal PEEP as well as its determination, most randomized control trials of high versus low PEEP failed to show any benefit in patients with ARDS. ${ }^{21}$ This is particularly because of the inability to recognize recruitability of lungs. The clinical application of lungprotective strategies continues to evolve and so does the understanding of VILI. This is particularly important because the mortality in ARDS has plateaued over past 2 decades.

\section{Heart-Lung Interactions Can Contribute to VILI}

In a recent paper, Katira et $\mathrm{al}^{22}$ repeated the classic work by Webb and Tierney ${ }^{7}$ and studied hemodynamics by using echocardiography, right and left ventricular pressures. The original work demonstrated that healthy rats, when ventilated with high inflation pressures without PEEP, resulted in fatal pulmonary edema. ${ }^{7}$ This was demonstrated again in our study, ${ }^{22}$ and florid pulmonary edema prompted the likelihood of a hemodynamic mechanism. Two important patterns of heart-lung interactions were observed:

1. During each respiratory cycle (peak inspiratory pressure, $45 \mathrm{~cm} \mathrm{H}_{2} \mathrm{O}$, PEEP $0 \mathrm{~cm} \mathrm{H}_{2} \mathrm{O}$ ), the pulmonary blood flow was completely obliterated during inspiration and exaggerated during expiration. Combined results from echocardiography and right ventricular pressure measurements indicated that, during inspiration, the right ventricular cavity was completely obliterated due to mechanical compression from the inflating lung. During expiration, the right heart was overfilled, with resultant high pulmonary blood flow. The pulmonary vascular bed, therefore, had a high flow-no flow-high 
Table 1. Mechanisms of VILI During PPV in Patients With De Novo Respiratory Failure

\begin{tabular}{|c|c|c|c|}
\hline Mechanisms of VILI & PPV Parameter & $\begin{array}{c}\text { Management During Invasive } \\
\text { Ventilation }\end{array}$ & Management During NIV \\
\hline Volutrauma & High $V_{T}$ & Lowering $\mathrm{V}_{\mathrm{T}}$ & $\begin{array}{l}\text { If } \mathrm{V}_{\mathrm{T}} \text { continues to be high, then } \\
\text { abort NIV and intubate early }\end{array}$ \\
\hline Biotrauma & High $\mathrm{V}_{\mathrm{T}}$ and low PEEP & Lower $\mathrm{V}_{\mathrm{T}}$ and optimize PEEP & $\begin{array}{l}\text { If VT continues to be high, then } \\
\text { abort NIV and intubate early }\end{array}$ \\
\hline Adverse heart-lung interaction & High $\mathrm{V}_{\mathrm{T}}$ and low PEEP & Lower $\mathrm{V}_{\mathrm{T}}$ and optimize PEEP & $\begin{array}{l}\text { If VT continues to be high, then } \\
\text { abort NIV and intubate early }\end{array}$ \\
\hline Lung deflation injury & Abrupt disconnections & $\begin{array}{l}\text { Avoid open suction slow } \\
\text { lowering of PEEP }\end{array}$ & $\begin{array}{l}\text { Avoid multiple and abrupt removals } \\
\text { of the NIV interface* }\end{array}$ \\
\hline Effort-induced lung injury & High diaphragmatic effort & $\begin{array}{l}\text { Sedation, paralysis, treat acidosis, } \\
\text { adequate recruitment, prone } \\
\text { positioning, avoid double } \\
\text { triggering }\end{array}$ & $\begin{array}{l}\text { Judicious sedation, optimize EPAP, } \\
\text { treat acidosis } \\
\text { If high effort persists, then abort } \\
\text { NIV and intubate early }\end{array}$ \\
\hline \multicolumn{4}{|c|}{$\begin{array}{l}\text { Various mechanisms are involved in VILI genesis and are incited by a specific PPV parameter; physiologically, these mechanisms can affect lungs during invasive and NIV alike, however, the } \\
\text { management may slightly differ, as shown here. } \\
\text { * This mechanism needs further confirmation. } \\
\text { VILI = ventilator-induced lung injury } \\
\text { PPV = positive-pressure ventilation } \\
\mathrm{V}_{\mathrm{T}}=\text { tidal volume } \\
\text { NIV = noninvasive ventilation } \\
\text { EPAP = expiratory positive airway pressure }\end{array}$} \\
\hline
\end{tabular}

flow state. Such a pattern was consistent with vascular shearing, which was known to cause endothelial injury (capillary stress failure). Endothelial injury would facilitate microvascular leakage of protein and water into the alveoli, which results in high permeability pulmonary edema.

2. Over the course of the experiment $(20 \mathrm{~min})$ right heart failure developed and right ventricular volume increased, which shifted the interventricular septum into the left ventricle. This resulted in increased left ventricular enddiastolic pressure (back pressure for pulmonary capillaries), which facilitated edema formation.

Together these 2 observations indicated that high $\mathrm{V}_{\mathrm{T}}$ ventilation (as in the original and classic paper ${ }^{7}$ ) is accompanied with adverse heart lung interactions, which result in injurious degrees of hemodynamic forces that contribute to VILI genesis. These observations are important because they indicate cardiovascular targets in addition to respiratory targets to achieve lung protection Table 1 .

In the context of NIV, vascular flows are likely to depend on 2 issues. First, the effort of breathing, which would determine the $\mathrm{V}_{\mathrm{T}}$. If the $\mathrm{V}_{\mathrm{T}}$ is high, then the vascular flow will undergo significant changes with each breath (eg, in patients with asthma). If the effort and therefore the $\mathrm{V}_{\mathrm{T}}$, are reduced with NIV support, then the vascular flows may not be harmful. Second, diaphragm tone is maintained in NIV and may act as PEEP, which thus protects against heavy vascular flows, provided that the effort and $\mathrm{V}_{\mathrm{T}}$ improve Table 1.

\section{Lung Deflation Injury}

In yet another study, Katira et al discovered a new mechanism of potential harm during mechanical ventilation. ${ }^{23}$ Because it is associated with abrupt release of airway pressure, we termed it lung deflation injury. ${ }^{23}$ In multiple series of experiments that used healthy in vivo rats, abrupt removal of PEEP after sustained inflation was associated with poor lung compliance, poor oxygenation, increased lung water, and inflammation. The primary injury was to the endothelium along with alveolar edema. Given the sudden development of edema, a hemodynamic mechanism was postulated. Results from echocardiography, right and left ventricular pressures indicated 2 possible hemodynamic forces that contribute to lung injury:

1. With sustained inflation, the cardiac output reduces but the systemic vascular resistance increases to maintain blood pressure. With abrupt deflation, the cardiac output abruptly increases, however, the systemic vascular resistance does not relax as quickly. As a result, the filled left ventricle now ejects a large volume of blood against heavy resistance and causes a left ventricularafterload mismatch. This leads to increased left ventricular filling pressure (left ventricular end-diastolic pressure) and, therefore, a high back pressure in the pulmonary capillaries. The left ventricular end-diastolic pressure in these animals was high enough to have caused endothelial injury.

2. Another hemodynamic force that contributes to injury formation is the high forward pulmonary blood flow, 
which results in an acute rise in forward capillary pressure to the point of causing capillary injury.

Together, these altered hemodynamic forces result in capillary stress failure, microvascular leak, and inflammation. Inflation forces in the alveoli have been extensively studied and are causative for VILI. ${ }^{24-26}$ However, this study illustrated that lung deflation can be associated with injury; this is important because abrupt deflation may happen many times during mechanical ventilation, especially with suctioning and transport. In addition, several studies of lung inflation were negative ${ }^{21}$; there could be a potential contribution of deflation injury to those negative or equivocal outcomes. Although it is too early to say whether deflation injury occurs in the clinical situation, there is a concern, especially in patients with ARDS, about additional injury during suction and tube disconnections. This may be true of NIV too if the expiratory positive airway pressure is high.

\section{Effort-Induced Lung Injury}

Early paralysis in patients with ARDS has been shown to improve lung function and mortality. ${ }^{27-29}$ Results of a multi-center randomized control trial showed less barotrauma and better survival in subjects with neuromuscular blockade. ${ }^{27}$ Similarly, in subjects with severe sepsis, mortality was lower with paralysis. ${ }^{30}$ As opposed to that, a post hoc analysis of the large observational study to understand the global impact of severe acute respiratory failure (LUNG SAFE) study ${ }^{31}$ demonstrated that subjects with severe ARDS did worse with NIV. ${ }^{32}$ A single-center randomized control trial of airway pressure release ventilation, which allows more spontaneous breathing versus conventional ventilation, in pediatric subjects with ARDS demonstrated higher mortality with airway pressure release ventilation. ${ }^{33}$ Together, results of these studies indicate an injurious contribution of spontaneous breathing during mechanical ventilation, especially in patients with acute lung injury.

Several mechanisms of harm were discerned:

1. Spontaneous breathing on the ventilator decreases pleural pressure and increases transpulmonary pressure, and, therefore, for the same mechanical properties of the lung, it increases $\mathrm{V}_{\mathrm{T}} \cdot{ }^{34}$ During pressure-targeted ventilation, this increases the chances of barotrauma without necessarily changing the plateau pressure. Under conditions of lung injury, these changes can be significantly detrimental.

2. Spontaneous effort in conditions of lung injury induces a phenomenon of pendelluft (ie, exchange of gas from non-dependent to dependent areas due to differential changes in pleural pressure). Under normal conditions, spontaneous effort induces a uniform change in pleural pressure throughout inspiration, which results in a uniform change in transpulmonary pressure. However, with injured lungs, the spontaneous effort results in higher and earlier negative pleural pressure in the dependent regions compared with non-dependent regions (lower and later). This results in air moving from non-dependent regions to dependent in the early phase of inspiration. The distention that results from such pendelluft could result in significant tidal recruitment of dependent regions and worsen an existing lung injury. ${ }^{35}$

3. Spontaneous effort generates negative pleural pressure, which results in overall negative intrathoracic pressure. This increases venous return and lung perfusion, which causes high intravascular pressure. This coupled with negative pleural pressure leads to high transvascular pressure (pressure inside the vessel - pressure outside the vessel [ie, pleural pressure]). ${ }^{36}$ During volume-cycled ventilation, spontaneous effort results in lowering of airway pressure and in increasing transvascular pressure, which thus causes a propensity toward edema formation. ${ }^{37}$

4. Spontaneous effort can also induce patient-ventilator asynchrony, with some evidence toward worsening mortality. Especially in a condition of double ${ }^{38}$ or reverse triggering ${ }^{39}$ the delivered $\mathrm{V}_{\mathrm{T}}$, and the transpulmonary pressure can be higher and, despite lung-protective strategies, may worsen lung injury and outcomes.

Beneficial effects of spontaneous breathing, spontaneous effort, if not excessive, maintains diaphragm muscle tone and function. ${ }^{40}$ Muscle paralysis induces diaphragm dysfunction, which results in difficult weaning. ${ }^{41}$ It also increases right ventricular preload and may reduce right ventricular afterload, which results in overall better lung perfusion. This, in the setting pulmonary hypertension or mild lung injury, may be beneficial to improve ventilationperfusion ( $\dot{\mathrm{V} / \mathrm{Q}}$ ) match. In the presence of mild injury and well-recruited lungs, spontaneous effort reduces further injury and, by improving ventilation to dependent areas (well-perfused areas), improves Vं/Q match. ${ }^{42,43}$

Therefore, at the bedside, a judicious approach toward assessing spontaneous effort can help minimize injury to improve outcomes. To facilitate this, regular use of esophageal manometry to measure the occurrence and strength of spontaneous effort is recommended. Good sedation and analgesia can significantly reduce heavy effort, and neuromuscular blockade would completely abolish it. In addition, adequate recruitment flattens the diaphragm, changes the force-length relationship, and reduces the degree of effort. The same can be true of using the prone position during mechanical ventilation. Correc- 
tion of acidosis and extracorporeal removal of $\mathrm{CO}_{2}$ can facilitate reduction of spontaneous effort. Detection and avoidance of patient-ventilator asynchrony with proper selection of mode and ventilators settings may help reduce effort-related change in lung inflation. ${ }^{44}$ These physiologic mechanisms of effort-induced injury or benefit are likely common between invasive ventilation and NIV and, hence, principles to prevent harm and enhance benefit would be similar, certainly, with the exception of deep sedation, paralysis, and use of extracorporeal membrane oxygenation.

\section{Summary}

Classically, VILI has been recognized as the result of high airway forces (high plateau pressure and $\mathrm{V}_{\mathrm{T}}$ ) and modulation of this is now recommended during ventilation for patients with ARDS. Changes in vascular forces (especially vascular shearing) from adverse heart-lung interactions can synergize with airway forces to augment lung injury. Abrupt disconnections can be a potential contributor toward harm; however, more data are needed to confirm this. Also, heavy spontaneous effort in the presence of severe lung injury can significantly worsen outcomes, and, hence, modulation of this is most desirable. There are risks associated with the delivery of NIV in patients who are hypoxemic, particularly those with ARDS. However, its use to treat patients with ARDS is surprising high globally. The previously mentioned the large observational study reported regular use of NIV for ARDS and worse outcomes related to the severity of ARDS. ${ }^{31,32}$ In these patients, as discussed, it makes physiologic sense that the same concepts of heart and lung interactions, deflation injury, and excessive effort could contribute to lung injury. ${ }^{16}$ During NIV, inspiratory pressure is maintained, and, when effort increases, the associated drop in pleural pressure will increase transpulmonary pressure, which contributes to lung strain, especially if the degree of lung injury is heterogenous. Although the monitoring of effort with the placement of catheters can be challenging in awake spontaneously breathing patients, the monitoring of $\mathrm{V}_{\mathrm{T}}$ may be a useful tool in patients with hypoxemic respiratory failure who are being managed with NIV. ${ }^{19}$ Although this has not been assessed in a prospective randomized trial, it could provide additional feedback to the potential excessive effort and lung stress generated by the patient.

\section{ACKNOWLEDGMENTS}

The author thanks Brian Kavanagh MD, and Thomas Piraino RRT FCSRT for reviewing the paper and making useful suggestions.

\section{REFERENCES}

1. Ibsen B. The anaesthetist's viewpoint on the treatment of respiratory complications in poliomyelitis during the epidemic in Copenhagen. Proc R Soc Med 1954;47(1):72-74.
2. MacIntyre N. Design features of modern mechanical ventilators. Clin Chest Med 2016;37(4):607-613.

3. Slutsky AS. History of mechanical ventilation. From Vesalius to ventilator-induced lung injury. Am J Respir Crit Care Med 2015; 191(10):1106-1115.

4. Tremblay LN, Slutsky AS. Ventilator-induced lung injury: from the bench to the bedside. Intensive Care Med 2006;32(1):24-33.

5. Faridy EE, Permutt S, Riley RL. Effect of ventilation on surface forces in excised dogs' lungs. J Appl Physiol 1966;21(5):1453-1462.

6. Mead J, Takishima T, Leith D. Stress distribution in lungs: a model of pulmonary elasticity. J Appl Physiol 1970;28(5):596-608.

7. Webb HH, Tierney DF. Experimental pulmonary edema due to intermittent positive pressure ventilation with high inflation pressures. Protection by positive end-expiratory pressure. Am Rev Respir Dis 1974;110(5):556-565.

8. Parker JC, Townsley MI, Rippe B, Taylor AE, Thigpen J. Increased microvascular permeability in dog lungs due to high peak airway pressures. J Appl Physiol Respir Environ Exerc Physiol: 1984;57(6): 1809-1816.

9. Dreyfuss D, Basset G, Soler P, Saumon G. Intermittent positivepressure hyperventilation with high inflation pressures produces pulmonary microvascular injury in rats. Am Rev Respir Dis 1985;132(4): 880-884.

10. Dreyfuss D, Soler P, Basset G, Saumon G. High inflation pressure pulmonary edema. Respective effects of high airway pressure, high tidal volume, and positive end-expiratory pressure. Am Rev Respir Dis 1988;137(5):1159-1164.

11. Hernandez LA, Peevy KJ, Moise AA, Parker JC. Chest wall restriction limits high airway pressure-induced lung injury in young rabbits. J Appl Physiol (1985) 1989;66(5):2364-2368.

12. Hickling KG, Henderson SJ, Jackson R. Low mortality associated with low volume pressure limited ventilation with permissive hypercapnia in severe adult respiratory distress syndrome. Intenive Care Med 1990;16(6):372-377.

13. Hickling KG, Walsh J, Henderson S, Jackson R. Low mortality rate in adult respiratory distress syndrome using low-volume, pressurelimited ventilation with permissive hypercapnia: a prospective study. Crit Care Med 1994;22(10):1568-1578.

14. Tremblay L, Valenza F, Ribeiro SP, Li J, Slutsky AS. Injurious ventilatory strategies increase cytokines and c-fos m-RNA expression in an isolated rat lung model. J Clin Invest 1997;99(5):944-952.

15. Ranieri VM, Suter PM, Tortorella C, De Tullio R, Dayer JM, Brienza A, et al. Effect of mechanical ventilation on inflammatory mediators in patients with acute respiratory distress syndrome: a randomized controlled trial. JAMA 1999;282(1):54-61.

16. Slutsky AS, Ranieri VM. Ventilator-induced lung injury. N Engl J Med 2013;369(22):2126-2136.

17. Amato MB, Barbas CS, Medeiros DM, Magaldi RB, Schettino GP, Lorenzi-Filho G, et al. Effect of a protective-ventilation strategy on mortality in the acute respiratory distress syndrome. N Engl J Med 1998;338(6):347-354.

18. Acute Respiratory Distress Syndrome Network, Brower RG, Matthay MA, Morris A, Schoenfeld D, Thompson BT, Wheeler A. Ventilation with lower tidal volumes as compared with traditional tidal volumes for acute lung injury and the acute respiratory distress syndrome. The Acute Respiratory Distress Syndrome Network. N Engl J Med 2000;342(18):1301-1308.

19. Carteaux G, Millán-Guilarte T, De Prost N, Razazi K, Abid S, Thille AW, et al. Failure of noninvasive ventilation for de novo acute hypoxemic respiratory failure: role of tidal volume. Crit Care Med 2016;44(2):282-290.

20. Brochard L, Slutsky A, Pesenti A. Mechanical ventilation to minimize progression of lung injury in acute respiratory failure. Am J Respir Crit Care Med 2017;195(4):438-442. 


\section{VENTILATOR-INDUCED LUNG INJURY}

21. Briel M, Meade M, Mercat A, Brower RG, Talmor D, Walter SD, et al. Higher vs lower positive end-expiratory pressure in patients with acute lung injury and acute respiratory distress syndrome: systematic review and meta-analysis. JAMA 2010;303(9):865-873.

22. Katira BH, Giesinger RE, Engelberts D, Zabini D, Kornecki A, Otulakowski G, et al. Adverse heart-lung interactions in ventilatorinduced lung injury. Am J Respir Crit Care Med 2017;196(11):14111421.

23. Katira BH, Engelberts D, Otulakowski G, Giesinger RE, Yoshida T, Post M, et al. Abrupt deflation after sustained inflation causes lung injury. Am J Respir Crit Care Med 2018;198(9):1165-1176.

24. Egan EA. Response of alveolar epithelial solute permeability to changes in lung inflation. J Appl Physiol Respir Environ Exerc Physiol 1980;49(6):1032-1036.

25. Egan EA. Lung inflation, lung solute permeability, and alveolar edema. J Appl Physiol Respir Environ Exerc Physiol 1982;53(1): 121-125.

26. Egan EA, Nelson RM, Olver RE. Lung inflation and alveolar permeability to non-electrolytes in the adult sheep in vivo. J Physiol 1976;260(2):409-424

27. Papazian L, Forel JM, Gacouin A, Penot-Ragon C, Perrin G, Loundou A, et al.; ACURASYS Study Investigators. Neuromuscular blockers in early acute respiratory distress syndrome. N Engl J Med 2010; 363(12):1107-1116

28. Gainnier M, Roch A, Forel JM, Thirion X, Arnal JM, Donati S, Papazian L. Effect of neuromuscular blocking agents on gas exchange in patients presenting with acute respiratory distress syndrome. Crit Care Med 2004;32(1):113-119.

29. Forel JM, Roch A, Marin V, Michelet P, Demory D, Blache JL, et al. Neuromuscular blocking agents decrease inflammatory response in patients presenting with acute respiratory distress syndrome. Crit Care Med 2006;34(11):2749-2757.

30. Steingrub JS, Lagu T, Rothberg MB, Nathanson BH, Raghunathan $\mathrm{K}$, Lindenauer PK. Treatment with neuromuscular blocking agents and the risk of in-hospital mortality among mechanically ventilated patients with severe sepsis. Crit Care Med 2014;42(1):90-96.

31. Bellani G, Laffey JG, Pham T, Fan E, Brochard L, Esteban A, et al.; LUNG SAFE Investigators, ESICM Trials Group. Epidemiology, patterns of care, and mortality for patients with acute respiratory distress syndrome in intensive care units in 50 countries JAMA 2016;315(8):788-800

32. Bellani G, Laffey JG, Pham T, Madotto F, Fan E, Brochard L, et al.; LUNG SAFE Investigators, ESICM Trials Group. Noninvasive ventilation of patients with acute respiratory distress syndrome. Insights from the LUNG SAFE study. Am J Respir Crit Care Med 2017; 195(1):67-77.

33. Lalgudi Ganesan S, Jayashree M, Chandra Singhi S, Bansal A. Airway pressure release ventilation in pediatric acute respiratory dis- tress syndrome. A randomized controlled trial. Am J Respir Crit Care Med 2018;198(9):1199-1207.

34. Akoumianaki E, Maggiore SM, Valenza F, Bellani G, Jubran A, Loring SH, et al.; PLUG Working Group (Acute Respiratory Failure Section of the European Society of Intensive Care Medicine). The application of esophageal pressure measurement in patients with respiratory failure. Am J Respir Crit Care Med 2014;189(5):520531.

35. Yoshida T, Torsani V, Gomes S, De Santis RR, Beraldo MA, Costa EL, et al. Spontaneous effort causes occult pendelluft during mechanical ventilation. Am J Respir Crit Care Med 2013;188(12):14201427.

36. Mauri T, Yoshida T, Bellani G, Goligher EC, Carteaux G, Rittayamai N, et al.; PLeUral pressure working Group (PLUG-Acute Respiratory Failure section of the European Society of Intensive Care Medicine. Esophageal and transpulmonary pressure in the clinical setting: meaning, usefulness and perspectives. Intensive Care Med 2016;42(9):1360-1373.

37. Kallet RH, Alonso JA, Luce JM, Matthay MA. Exacerbation of acute pulmonary edema during assisted mechanical ventilation using a low-tidal volume, lung-protective ventilator strategy. Chest 1999; 116(6): 1826-1832

38. Pohlman MC, McCallister KE, Schweickert WD, Pohlman AS, Nigos CP, Krishnan JA, et al. Excessive tidal volume from breath stacking during lung-protective ventilation for acute lung injury. Crit Care Med 2008;36(11):3019-3023.

39. Akoumianaki E, Lyazidi A, Rey N, Matamis D, Perez-Martinez N, Giraud R, et al. Mechanical ventilation-induced reverse-triggered breaths: a frequently unrecognized form of neuromechanical coupling. Chest 2013;143(4):927-938

40. Sassoon CS, Zhu E, Caiozzo VJ. Assist-control mechanical ventilation attenuates ventilator-induced diaphragmatic dysfunction. Am J Respir Crit Care Med 2004;170(6):626-632.

41. Levine S, Nguyen T, Taylor N, Friscia ME, Budak MT, Rothenberg $\mathrm{P}$, et al. Rapid disuse atrophy of diaphragm fibers in mechanically ventilated humans. N Engl J Med 2008;358(13):1327-1335.

42. Wrigge H, Zinserling J, Neumann P, Defosse J, Magnusson A, Putensen C, Hedenstierna G. Spontaneous breathing improves lung aeration in oleic acid-induced lung injury. Anesthesiology 2003; 99(2):376-384.

43. Neumann P, Wrigge H, Zinserling J, Hinz J, Maripuu E, Andersson LG, et al. Spontaneous breathing affects the spatial ventilation and perfusion distribution during mechanical ventilatory support. Crit Care Med 2005;33(5):1090-1095.

44. Yoshida T, Fujino Y, Amato MB, Kavanagh BP. Fifty years of research in ARDS. Spontaneous breathing during mechanical ventilation. risks, mechanisms, and management. Am J Respir Crit Care Med 2017;195(8):985-992

\section{Discussion}

Davies: Thank you, Bhushan. I have a question or maybe a comment. You mentioned that the abrupt disconnection or removal of pressure in NIV can have a deleterious effect. In many instances, we encourage patients to take the mask off to eat or for aerosolized medication delivery. I wonder if we are doing them a disservice by doing that?
Katira: I don't have an answer because this was in normal rats that were paralyzed. ${ }^{1}$ So the lung might be suddenly deflated or there may be more vascular injury. Although this phenomenon has yet to be recognized in patients and may be different for awake patients because the diaphragmatic tone may not allow complete lung collapse (in other words, FRC may be maintained). This work certainly indicates that there is a cause for worry and that we need to identify which patient we should worry about.

Davies: I do think we need to keep in mind that abruptly removing them may come with deleterious consequences.

Strickland: To your point, John [Davies], maybe what we need to consider is not just removing NIV at a point for whatever care we need to 
give or for relief from the face mask or whatever, but, maybe as Frat et $\mathrm{al}^{2}$ suggested to start doing some sequential HFNC so that we can still provide some of the responses that we were getting with the NIV while also still giving the patients' face a break and giving them the chance to do some other activities and provide whatever care is needed and to potentially avoid this phenomenon.

Kacmarek: In your rat studies, you showed it going from 12 to 0 . How much of a change, and do you have to go all the way to 0 , for the effect to be seen? If I'm on 20 of PEEP and I go to 8 , do I see the same response as if I go from 12 to 0 ?

Katira: In rats, you don't. Leaving some end-expiratory pressure is protective, but these are rat studies. The effect that we showed was from 12 to 0 ; we need further study to appreciate this phenomenon. It would be very premature for me to say, "OK take these numbers and translate them to bedside."

Kacmarek: So, at this point in time, we really don't have a good handle on those types of injuries.

Katira: Yes, just appreciating that this phenomenon is happening in rats very consistently and might be happening in some patients. We just need to be mindful. But I don't know exactly what pressures or limits.

Nishimura: When we use airway pressure release ventilation (APRV), is it harmful?

Katira: There was a recent study in pediatric ARDS from India of subjects with acute lung injury (which was moderate-to-severe ARDS). ${ }^{3}$ They randomized subjects to APRV versus normal low $\mathrm{V}_{\mathrm{T}}$, high PEEP ventilation. ${ }^{3}$ Mortality doubled with APRV; it was $28 \%$ with low $\mathrm{V}_{\mathrm{T}}$ and adequate lung recruitment and was $56 \%$ with
APRV. ${ }^{3}$ Part of the problem was high spontaneous effort during APRV in addition to airway pressure release, both of which I have presented today and concerning. Mortality was a surrogate of ventilator-induced lung injury in this study.

* Hess: Back to your point, John. I wonder if it's a matter of what type of patient we are treating with NIV. I can imagine that, in a patient with COPD exacerbation, those removals of the mask periodically might be less injurious than in a patient with hypoxemic respiratory failure or cardiogenic pulmonary edema to whom we're providing NIV. I don't know if there are any data about that. But your data are primarily for animals with acute lung injury, it's not a model of COPD exacerbation.

Katira: These experiments were in normal rats; they were neither a model of COPD nor a model of lung injury. However, in pilot studies of pre-injured lung conditions, we observed that APRV exacerbates lung injury, and, thus, your point is well taken that it might be much more important in patients with hypoxemic respiratory failure. We also know from the LUNGSAFE study subgroup analysis ${ }^{4}$ that NIV was injurious in severe ARDS; the outcomes were worse compared with those with mild ARDS. So there is reason to believe that, in a subgroup of patients, especially in severe ARDS and significant hypoxemic respiratory failure, doing NIV early might be bad for a couple of reasons. Most important, I think is self-induced lung injury; but, apart from that, even high $\mathrm{V}_{\mathrm{T}}$, independent of distribution, might be injurious. Also, the hemodynamic effects are really less appreciated. Except for the HFOV trial, 5 in which there was significant hypotension, in most high PEEP studies, he-

* Dean R Hess PhD RRT FAARC, Managing Editor, RESPIRATORY CARE. modynamics were not even reported. We know that circulatory death (from right heart failure) is a strong predictor of mortality in ARDS.

Hill: I appreciate all of your caveats; clearly what you're working on is something we can't translate into the clinical setting yet for the number of reasons you've given. But we've made a lot of comments about NIV and hypoxemic respiratory failure, and some of the observations you've made may be relevant to how we use it. You pointed out the LUNGSAFE study, ${ }^{4}$ which did raise a lot of concerns about using NIV in severe ARDS, and, frankly, guidelines have not recommended that we use NIV in that setting. The most recent ATS/ERS guideline $^{6}$ made no recommendation. It wasn't a contraindication, some people have misinterpreted it as that, but we just didn't have enough data to make a recommendation one way or the other. But, having said that, we're using NIV quite often in patients with ARDS. Results of our studies showed rates of the use of NIV as the initial ventilator mode in some $40 \%$ of patients admitted to hospitals with pneumonia, ${ }^{7}$ especially elderly patients when there's a reluctance to intubate. One question I have for you is, given the reality of the situation, what can you say about the relevance of your observations to how we're using NIV in hypoxemic respiratory failure today. Clearly, we use a gentler approach than the one you're illustrating; we certainly don't go abruptly to 0 PEEP with NIV. If you're intubated and you're bypassing upper-airway mechanisms that maintain a "physiologic PEEP," you could theoretically go to 0 or even a negative PEEP, but we don't do that. So what is the clinical relevance of your observation?

Katira: Difficult question.

Hill: Of course. 
Katira: The practice of NIV is more of a spillover effect to all patient groups, and we have to identify when it should be beneficial and when it may not. From what I can conclude and the insights from all of these studies is at least in severe ARDS, say $\mathrm{P}_{\mathrm{aO}_{2}} / \mathrm{F}_{\mathrm{IO}_{2}}$ of $<100$ or $150 \mathrm{~mm} \mathrm{Hg}$, I would be de-recommending it unless more prospective trials show benefits. What we know is the acceptable time for NIV, whether it should be for 24$48 \mathrm{~h}$, or $36 \mathrm{~h}$, or $7 \mathrm{~d}$ (like some subjects in LUNGSAFE), ${ }^{4}$ which I think is a bit too far. I don't know the real target, but, I would say that, in severe ARDS, I would de-recommend NIV and recommend invasive ventilation, paralyze for the first 3 or $4 \mathrm{~d}$, put them prone, and get their lungs sorted; then exercise their diaphragm adequately and get them off the vent. In severe ARDS, I would like to intubate.

Hill: I think my question is a question without a clear answer, but I asked you to speculate. There are a couple of other observations in the literature that raise even more questions. One is the study by Patel et $\mathrm{al}^{8}$ which compared helmet versus standard face mask where the intubation rate was lowered from $62 \%$ with the face mask compared with $18 \%$ for the helmet. Different ventilators and settings were used for each interface, but it raised the question of whether the interface and settings make a big difference and that may alter what you're saying about how severe a patient's condition must be before we say he or she is too sick for NIV.

Kacmarek: I don't think, Nick [Hill], that it's necessarily the device that makes the difference; it's the patient's tolerance of the application. You and I have both had the helmet on, and I would clearly rather have the helmet on than a face mask strapped to my face. So it may be the ability of the patient to work with and tolerate the device, which is why
HFNC works better in many patients than NIV. It's a tolerance of the process and the overall patient response. But because we've all seen patients who are struggling with NIV, we're all at fault for not interacting and changing the approach to ventilating them sooner. I can guarantee you that if we walked around any hospital, we'd find a few patients who should be intubated who are being maintained either on NIV or HFNC but are working their butt off and are in severe ARDS, and nobody wants to accept that because their $\mathrm{P}_{\mathrm{O}_{2}}$ is normal.

Hill: Clearly intolerance of the face mask has been a major impediment to the success of NIV. Whether that's the whole explanation for the different responses to the helmet and the face mask, I'm not sure, but it's part of it, and synchrony is a big deal as well.

Scott: First of all, excellent presentation. I wanted to ask a question about time, thinking about those of us in the emergency department who use NIV for acute cardiogenic pulmonary edema. Is NIV lung injury a product of time? What relationship does time have on lung injury? I ask because some patients in the emergency department only require NIV support for hours versus days as in the ICU.

Katira: Again, it's very difficult to answer that question, at least for individualized patients. If there's a sense that the effort is very strong despite adequate support, then maybe this is a patient for whom you should now go ahead, and if there's a sense that effort has reduced (eg, by ultrasound assessment of diaphragm), then we could continue to use NIV. This is not based on any prospective study or work but just thinking if you want to do something to titrate ventilation based on patient effort. To say that all patients should be $\geq 4 \mathrm{~d}$ or should all be $\leq 6 \mathrm{~h}$ sounds not applicable in the era of personalized medicine. There may be some patients even in severe ARDS who would clearly tolerate, and we should go ahead, and there may be some with COPD who would not tolerate it. Therefore, what we need to understand is if there are ways that we can measure returning $\mathrm{V}_{\mathrm{T}}$ during NIV (very high, say $10 \mathrm{~mL} \mathrm{~V}_{\mathrm{T}}$ can be injurious) and the diaphragmatic activity, for example, by ultrasound (again if very high can be detrimental), so that we can titrate the ventilation time and method (NIV versus invasive). Recognizing an injurious pattern of ventilation early is very important. What time and how much time, it's very difficult to say at this stage.

\section{REFERENCES}

1. Katira BH, Engelberts D, Otulakowski G, Giesinger RE, Yoshida T, Post M, et al. Abrupt deflation after sustained inflation causes lung injury. Am J Respir Crit Care Med 2018;198(9):1165-1176.

2. Frat JP, Brugiere B, Ragot S, Chatellier D, Veinstein A, Goudet V, et al. Sequential application of oxygen therapy via high-flow nasal cannula and noninvasive ventilation in acute respiratory failure: an observational study. Respir Care 2015; 60(2):170-178.

3. Lalgudi Ganesan S, Jayashree M, Chandra Singhi S, Bansal A. Airway pressure release ventilation in pediatric acute respiratory distress syndrome: a randomized controlled trial. Am J Respir Crit Care Med 2018;198(9):1199-1207.

4. Bellani G, Laffey JG, Pham T, Madotto F, Fan E, Brochard L, et al.; LUNG SAFE Investigators, ESICM Trials Group. Noninvasive ventilation of patients with acute respiratory distress syndrome. Insights from the LUNG SAFE Study Am J Respir Crit Care Med 2017;195(1):67-77.

5. Ferguson ND, Cook DJ, Guyatt GH, Mehta S, Hand L, Austin P, et al.; OSCILLATE Trial Investigators, Canadian Critical Care Trials Group. High-frequency oscillation in early acute respiratory distress syndrome. N Engl J Med 2013;368(9): 795-805.

6. Rochwerg B, Brochard L, Elliott MW, Hess DR, Hill NS, Nava S, et al.; Raoof S Members Of The Task Force. Official ERS/ATS clinical practice guidelines: noninvasive ventilation for acute respiratory failure. Eur Respir J 2017;50(2). pii: 1602426. 
7. Ozsancak Ugurlu A, Sidhom SS, Khodabandeh A, Ieong M, Mohr C, Lin DY, et al. Use and outcomes of noninvasive positive pressure ventilation in acute care hospitals in Massachusetts. Chest 2014;145(5):964971.

8. Patel BK, Wolfe KS, MacKenzie EL, Salem D, Esbrook CL, Pawlik AJ, et al. One-year outcomes in patients with acute respiratory distress syndrome enrolled in a randomized clinical trial of helmet versus facemask noninvasive ventilation. Crit Care Med 2018; 46(7):1078-1084.

9. Papazian L, Forel JM, Gacouin A, PenotRagon C, Perrin G, Loundou A, et al; ACURASYS Study Investigators. Neuro- muscular blockers in early acute respiratory distress syndrome. N Eng1 J Med 2010; 363(12):1107-1116.

10. Katira BH, Giesinger RE, Engelberts D, Zabini D, Kornecki A, Otulakowski G, et al. Adverse heart-lung interactions in ventilator-induced lung injury. Am J Respir Crit Care Med 2017;196(11):1411-1421.

This article is approved for Continuing Respiratory Care Education credit. For information and to obtain your CRCE

(free to AARC members) visit

www.rcjournal.com 